\title{
Paguyuban sebagai Media Transformasi Sosial-ekonomi Keluarga Perempuan TKI Purna Penempatan? Sebuah Perspektif Antropologi Migrasi
}

\author{
Setiadi \\ Departemen Antropologi, Fakultas IImu Budaya, Universitas Gadjah Mada, dan Pusat Studi \\ Kependudukan dan Kebijakan, Universitas Gadjah Mada, Yogyakarta \\ Korespondensi: Setiadi (e-mail: setiadi_antro@ugm.ac.id)
}

\begin{abstract}
Abstrak
Fenomena Feminisasi Tenaga Kerja Indonesia telah menempatkan perempuan pada posisi strategis dalam keluarga. Salah satu penyebabnya adalah adanya sejumlah remitan ekonomi dan sosial yang mereka miliki. Jumlah remitan yang besar membutuhkan adanya optimalisasi pemanfaatan remitan melalui kewirausahaan ekonomi dan sosial. Keberhasilan penguatan kehidupan sosialekonomi TKI perempuan purna penempatan ini merupakan hal yang strategis. Namun studi ini membuktikan bahwa remitan fisik (uang) maupun sosial (jaringan) perempuan purna penempatan ternyata tidak meningkatkan atau menguatkan peran ekonominya. Artikulasi peran dan posisi TKI purna perempuan dalam keluarga dan masyarakat dalam mengembangkan usaha (kewirausahaan sosial dan ekonomi) kurang memiliki pengaruh signifikan. Mengapa kewirausahaan tenaga kerja perempuan purna penempatan gagal tercapai? Studi dengan pendekatan antropologi migrasi ini membuktikan bahwa ada tiga hal penting yang mempengaruhi hal tersebut, yakni rendahnya kemampuan perempuan untuk menggunakan akumulasi pendapatan selama bekerja di luar negeri dan kondisi relasi gender internal keluarga yang berpengaruh pada relasi kuasa dan rendahnya kapasitas fasilitas dari institusi perubahan sosial terhadap para keluarga migran.
\end{abstract}

Kata kunci: remitan; TKI perempuan purna penempatan; kewirausahaan; pendekatan antropologi 


\title{
Community Association as a Media for Family Socio-economic Transformation of Retiring Female Indonesian Workers? An Anthropological Perspective on Migration
}

\begin{abstract}
The Phenomenon of Feminization of Indonesian Workers has placed women in strategic positions in the family. One reason is the number of economic and social remittances they have. The great number of remittances requires the optimization of the utilization of remittances through economic and social entrepreneurship. The success of strengthening this Retiring Female Indonesian Workers is a strategic matter. In the long run, there will be an increase in the quality of life of the Indonesian workers' households. However, this study proves that Remitan and the social (network) of retiring women do not necessarily increase or strengthen their economic roles. The articulation of the roles and position of retiring female Indonesian workers (migrants) in the family and community in developing businesses (social and economic entrepreneurship) lacks significant influence. Why has the entrepreneurship of retiring female workers failed to be achieved? This study with the anthropological approach to migration proves that there are three important factors that influence it, i.e.the low capacity of female migrants to using the accumulation of income while working abroad and the internal conditions of family gender relations, and the low facilitation capacity of institutions/agencies for social change towards migrant families.
\end{abstract}

Keywords: remittances; retiring Female Indonesian Workers; entrepreneurship; anthropological approach

\section{Pengantar}

Migrasi penduduk merupakan salah satu strategi keluar dari kemiskinan dengan cepat (Asriani \& Amalia, 2014) melalui remitan (Hugo, 2002) sehingga mampu meningkatkan kesejahteraan, baik untuk dirinya maupun keluarganya (Sugito, Windiasih, \& Sulaiman, 2018). Namun demikian, ada banyak kendala untuk sampai pada tingkat peningkatan kesejaheraan. Salah satunya adalah sebagian TKI purna penempatan belum mampu memanfaatkan hasil bekerja untuk hal yang produktif (Prihanto, 2014). Masih banyak remitan untuk pemenuhan kebutuhan konsumtif (Muntamah, Latifiani, \&Arifin, 2016). Beberapa kasus, remitan terpaksa digunakan untuk membangun rumah agar terbebas dari bencana banjir (Sagala, Pratama, \& Argo, 2016). Kemampuan mengelola remitan penting untuk dimiliki agar rumah tangga migran memperoleh kesejahteraan (Sulistyono, 2015) dan memberi kesempatan mereka untuk mengembangkan usaha (Susilo, 2018). Dengan demikian, upaya pemberdayaan harus dilakukan. Pembekalan pengetahuan tentang kewirausahaan menjadi penting bagi TKI dan keluarganya agar remitansi dapat dimanfaatkan untuk usahausaha produktif (Jaya \& Subrata, 2014; Romdiati, 2012; Primawati, 2011). Melalui pemberdayaan, TKI purna penempatan akan memiliki wadah agar mereka terhindar dari proses-proses marginalisasi ekonomi dan 
sosial serta mengembangkan potensi yang mereka miliki (Arifiartiningsih, 2016).

Data penempatan pekerja migran Indonesia pada tiga tahun terakhirmenunjukan angka yang masih tinggi pada pengiriman pekerja ke luar negeri. Data BPTKI tentang penempatan pekerja migran menunjukkan, pada periode tahun 2018-2020 (Februari) berturut-turut adalah 19,502 pekerja pada $2018,18,450$ pekerja pada 2019 , dan 17,757 pekerja pada 2020, dengan proporsi sebagian besar perempuan (sebanyak $70,12 \%$ di tahun 2018 dan 2019 serta 66,30\% pada tahun 2020). Selain itu, data juga menunjukkan beberapa daerah penyumbang pengiriman tenaga kerja, seperti Indramayu, Lombok Timur, Kabupaten Cirebon, Cilacap, Lombok Tengah, dan Ponorogo (BP2MI, 2020). Kecenderungan secara nasional juga tampak pada beberapa daerah non-utama, misalnya data migran di Madura menunjukkan hampir $70 \%$ buruh migran Madura adalah perempuan (Rahayu dkk., 2012), sekaligus fakta bahwa migran perempuan purna penempatan identik dengan tenaga yang kurang terampil, minim pengetahuan, dan keahlian, sehingga hanya mengandalkan remitan untuk memenuhi kebutuhan hidup. Meski demikian, ada kompleksitas dan kondisi paradoks TKI perempuan purna penempatan apabila mereka akan diberdayakan dengan meningkatkan kapasitas kewirausahaan. Pertama, mereka mengalami beban ganda, sebab mayoritas dari mereka adalah ibu rumah tangga yang memiliki kewajiban untuk mengurus suami dan anak (Rahmawati dkk., 2017), masih melekatnya area domistik rumah tangga pada pembagian dan peran kerjanya (Sudarsani dkk., 2015). Kedua, ada indikasi melemahnya kondisi ekonomi setelah berhenti bekerja di luar negeri (Fitra \& Rizana, 2019). Ketiga, sebagian TKI purna merupakan perempuan kepala rumah tanga. Perempuan sebagai pelaku usaha tetap dihadapkan pada peran dan tanggung jawab utamanya di ranah domestik, padahal pengembangan usaha mau tidak mau berurusan dengan ranah publik (Listyani \& Kharisma, 2006). Ada harapan bahwa melalui program memberdayaan perempuan, perempuan dapat meningkatkan pendapatan keluarga tanpa meninggalkan perannya sebagai ibu rumah tangga, yaitu perempuan kepala keluarga dapat keluar dari masalah dan dapat menunjukkan perubahan yang berarti (Putri \& Darwis, 2015). Keempat, perempuan pada kelompok ini tidak memiliki kemampuan mengelola pendapatan untuk kewirausahaan (Sukesi dkk., 2017), sementara remitan tetap dianggap berdampak positif bagi peningkatan status ekonomi keluarga, tingkat pendidikan anak, dan tingkat kesehatan anak (Basrowi, 2019).

Secara institusional, upaya-upaya nyata pemberdayaan TKI purna telah banyak dilakukan, antara lain di Banyumas (Dewi dkk., 2018), pelatihan bagi TKI di Hongkong (Komariah \& Kokom, 2019), program pengembangan inovasi melalui Program Desa Peduli Buruh Migran (DESBUMI) (Ariefianto \& Ulum, 2019), pemberdayaan melalui Kelompok Usaha Bersama (KUB) (Yuniriyanti dkk., 2019), pelatihan kegiatan kewirausahaan berbasis bisnis daring telah berhasil meningkatkan motivasi berwirausaha secara online dan tercapainya pemahaman peserta atas manajemen diri, pemahaman atas manajemen produk, produksi, dan pengemasan dan tercapainya pemahaman peserta atas manajemen harga, pemasaran, dan distribusi (Yusa dkk., 2018). Pada sisi lain, penguatan kelembagaan masih banyak menjadi pilihan, khususnya penguatan kebijakan maupun penguatan kelembagaan 
pada masyarakat pengirim Buruh Migran Indonesia (BMI) (T.R Wulan et al., 2018). Dalam pandangan TKI perempuan purna penempatan, pelatihan-pelatihan yang dilakukan dapat menambah kemauan seseorang untuk berwirausaha. Namun terkadang memang tidak tersalurkan karena fasilitas dan praktikum yang kurang (Abas \& Purnomo, 2017). Berdasarkan berbagai kajian yang ada, peran sosial bagi penguatan masyarakat (Meiliyana, 2019) belum banyak diungkap, khususnya bagaimana prosesproses pelibatan dan keterlibatan perempuan TKI purna penempatan, khususnya dalam berbagai kegiatan informal berbasis keswadayaan atau lembaga keswadayaan masyarakat (Pitoyo, 2006). Pelatihan kewirausahaan bagi para TKW purna akan mampu membentuk lingkungan usaha yang semakin meningkatkan kemauan berwirausaha (Kirana, Kusrini, \& Purwanto, 2017), melalui kegiatan perdagangan kecil (De Jong, 2000). Artikel ini menggunakan perspektif teori feminisme, khususnya isu bagaimana perempuan mengelola reproduksi ekonomi melalui siklus kehidupannya dan isu reproduksi sumberdaya manusia (Truong, 1996), melalui pengalaman selama bermigrasi untuk mampu memberikan pengaruh terhadap perubahan melalui pemberdayaan diri dan lingkungan (Katherine Gibson, 2001). Migrasi faktor pemicu transformasi sosial melalui peran jaringan sosial dan modal sosial (van Hear, 2010). Dalam konteks migran perempuan, aspek otonomi dan kapasitas dalam mengambil keputusan sangat penting (Nana \& Oishi, 2002). Berdasarkan perspektif ini, mengkaji perempuan migran yang tergabung dalam kegiatan paguyuban dapat dilihat berdasarkan kemampuan modal ekonomi dan modal sosial, kemampuan membedayakan diri dan lingkungan, serta kemampuan mengambil keputusan sebagai individu yang otonom. Melalui kerangka ini, artikel ini menjelaskan bagaimana perempuan TKI purna penempatan terlibat dan melibatkan diri dalam proses pemberdayaan, khususnya pada kelembagaan berbasis komunitas.

\section{Metodologi dan Metode Penelitian}

Artikel ini menjawab salah satu aspek dari apa yang dimaksud sebagai penelitian etnografis hubungan antara migrasi dan pembangunan (Chan, 2014) yang menekankan adanya evaluasi kritis atas berbagai aspek dalam kedua bidang dan berbagai bidang lainnya (Vertovec, 2007), isu-isu hegemoni antarkelompok (Lem, 2007), analisis gender (Mahler \& Pessar, 2006), dan isu yang lebih luas seperti diaspora (Hage, 2005). Pendekatan ini, sebagai sebuah pendekatan antropologi migrasi, juga dicirikan dengan kajian individu dan rumah tangga serta wilayah tertentu (Brettell, 2013). Dalam pandangan penulis, ciri pendekatan ini tepat untuk diterapkan untuk mengkaji bagaimana Perempuan TKI purna penempatan berkiprah dalam kegiatan paguyuban mantan TKI. Dengan menggalipandangan emikperempuan dalam deskripsi etnografis, penelitian ini mengungkap bagaimana keterlibatan perempuan migran purna penempatan dalam program peningkatan kewirausahaan melalui kelembagaan informal berbasis komunitas berupa Paguyuban TKI purna penempatan. Penelitian ini dilaksanakan di perdesaan Yogyakarta yang memiliki warga TKI purna penempatan yang menjadi anggota paguyuban. Paguyuban tersebut berupa perkumpulan informal para TKI purna penempatan yang diinisiasi oleh para anggota secara mandiri. Data dikumpulkan dengan beberapa metode pengumpulan data. Pertama, wawancara mendalam. Wawancara dilakukan pada 20 perempuan 
migran purna penempatan di Kabupaten Sleman dan Bantul. Informan dipilih dengan pertimbangan; mereka yang memenuhi criteria sebagai migrant purna, terlibat dalam kegiatan paguyuban dan pernah atau sedang memiliki usaha yang modalnya berasal dari hasil bekerja di luar negeri. Kedua, FGD dilakukan dua kali dengan anggota Paguyuban. Ketiga, observasi partisipasi. Metode ini diterapkan untuk melihat secara langsung kegiatan paguyuban dan berbagai pola interaksi serta pandangan perempuan. Keempat, studi literatur. Metode ini digunakan untuk memperoleh data-data dari hasil penelitian lain di Indonesia, khususnya yang sudah terpublikasi di jurnal-jurnal nasional dan perpustakaan yang bisa diakses secara daring. Salah satu sumber data untuk analisis adalah hasil transkrip wawancara yang ada di lampiran tesis tentang migrasi internasional (Imawan, 2016). Data media massa juga merupakan salah satu jenis data yang dikumpulkan. Dari serangkaian data yang terkumpul, peneliti melakukan analisis dengan melakukan kategorisasi untuk menemukan pola pandangan emik perempuan terkait kegiatan di paguyuban dan perannya bagi peningkatan kemampuan kewirausahaan.

\section{Hasil Penelitian}

Paguyuban sebagai Wadah Pertemuan dan Pemberdayaan Para TKI Purna

\section{Peran Pemerintah}

Data menunjukan bahwa para TKI purna penempatan belum sepenuhnya mandiri. Dalam hal perkembangan paguyuban, para anggota paguyuban masih banyak mengharapkan bantuan dari pemerintah. Berdasarkan pandangan para anggota paguyuban, peran pemerintah dan lembaga lain dalam perkembangan paguyuban adalah memberikan bantuan. Terkait hal ini, data menunjukkan bahwa perlu upaya yang intens bagi pengurus paguyuban agar bisa mengakses bantuan.

Ada sih (pernah), tapi biasanya saya hubungi (telepon) terus. Saya selama ini selalu punya solusi-solusi, karena dalam dua tahun saya buat organisasi ini, saya sudah dapat empat kali bantuan. Itu paling banyak karena setahun sudah dapat dua kali. Apalagi kemarin program dari kabupaten, yang turun itu ada 16 kelompok. Nah, 16 kelompok itu pengajuannya seperti ini, setiap kelompok itu terdiri dari 20 orang. Ada yang mendapatkan lima paket, otomatis lima paket itu kan untuk 20 orang. Sedangkan saya 20 orang itu dapat 20 paket. Karena itu kemarin saya itu diam saja. Ternyata ada yang dengar, kenapa kuliningrat dapat banyak? (146)

Paguyuban merupakan arena bagi peningkatan kewirausahaan TKI purna penempatan. Beberapa kajian menunjukkan, pada dasarnya mereka memiliki potensi tinggi sebagai calon wirausaha (Utama \& Handayani, 2019). Bahkan, faktor remitan sosial yang dimiliki dipercaya menjadi kekuatan bagi migran untuk memberdayakan lingkungannya (Wulan et.al., 2009). Di sisi lain, keberhasilan dalam pengembangan kewirausahaan migran dapat dilihat sebagai bentuk penyesuaian diri atas pengalaman bekerja di luar negeri, dapat menciptakan beragam model usaha, dan mengelola jaringan social secara individual maupun kelompok (Yuniarto, 2012). Berdasarkan berbagai kajian yang ada, tampak bahwa masyarakat mantan dan calon buruh migran 
memiliki potensi melakukan usaha di berbagai bidang, namun masih bersifat individual dan kelompok kecil, belum memiliki kesadaran membentuk kelompok usaha bersama untuk mengembangkan dan memperkuat kelembagaan, serta memiliki kekuatan mengusulkan program pemberdayaan, seperti penyuluhan, pelatihan serta pendampingan secara berkesinambungan kepada pemerintah desa (Windiasih \& Sugito, 2018). Untuk tujuan ini, peran pemerintah bersama pemangku kepentingan lainnya sangat diperlukan untuk mendorong transformasi buruh migran menuju wirausahawan handal dengan memperhatikan dimensi budaya untuk membentuk watak wirausahawan tangguh (Mihradi \& Siregar, 2018).

Keterlibatan TKI perempuan pada paguyuban TKI purna penempatan mengalami pasang surut. Paguyuban, sebagai salah satu wadah bagi para TKI purna untuk berkumpul dan bertukar informasi, serta sebagai sarana pembentukan unit-unit usaha yang didukung oleh program pemerintah terkait dengan pembedayaan TKI purna, memiliki dinamika kelembagaan yang khas. Inisiatif pemberdayaan TKI Purna dilakukan pemerintah melalui Balai Pelayanan Penempatan dan Perlindungan Tenaga Kerja Indonesia (BP3TKI) (BNP2TKI, 2017). Paguyuban sebagai wadah bagi migran yang sudah kembali diharapkan akan menjadi media program pendidikan kewirausahaan dari pemerintah dan difasilitasi oleh organisasi migran kembali dapat meningkatkan sinergi antara migrasi internasional dan pembangunan daerah (Anwar, 2015). Citacita dan keinginan pendirian paguyuban yang menjadi kajian ini selaras dengan beberapa temuan tersebut. Salah satu paguyuban TKI Purna yang menjadi contoh dalam studi ini adalah Paguyuban TKI Purna Perintis yang berlokasi di Desa Sabrangan, Sariharjo,
Bantul. Paguyuban ini berdiri pada tahun 2013 dan diketuai oleh Jumiran (55) yang merupakan TKI purna yang pernah bekerja di Malaysia. Di sisi ini, paguyuban dan bantuan pemerintah merupakan modal ekonomi dan kelembagaan yang strategis bagi peningkatan kapasitas ekonomi rumah tangga (BP3TKI, 2015).

Data wawancara terkait sejarah perkembangan Paguyuban Perintis menunjukkanbahwapadaawalnyapaguyuban mempunyai 19 anggota yang terdiri atas 11 laki-laki dan 8 perempuan. Kegiatan rutin yang dilakukan oleh Paguyuban Perintis diantaranya adalah arisan setiap bulan sekali dan simpan pinjam dengan dana wajib awal sebesar 500 ribu rupiah yang dibayarkan setiap putaran pertama arisan. Pada awalnya pengurus mewajibkan para anggota untuk meminjam dari uang simpanan wajib yang sudah terkumpul agar nantinya dana simpan pinjam atau "saham" bisa berkembang. Setiap seratus ribu rupiah yang dipinjam, dibebankan biaya jasa sebesar lima ribu rupiah. Salah satu anggota paguyuban mengatakan bahwa biaya tersebut dibebankan agar saham yang sudah ada dapat berkembang dan bertambah. Selain kegiatan rutin yang dilaksanakan setiap bulan, paguyuban ini juga pernah mendapatkan pelatihan dari Bimtek BNP2TKI berupa pelatihan kewirausahaan yang dilaksanakan di Yogyakarta. Data ini mengonfirmasi pemberitaan yang dicantumkan pada web BP3TKI Yogyakarta. Namun, informan menambahkan jika sudah tiga tahun ini, paguyuban mereka tidak mendengar adanya kabar mengenai pelatihan-pelatihan lainnya, bahkan pengurus dan anggota saat ini merasa kesulitan untuk mengajukan proposal pelatihan atau pengajuan bantuan akibat kurangnya pengetahuan tentang halhal tersebut. "Sepertinya, dorongan untuk mendirikan paguyuban tidak diikuti dengan 
perencanaan yang baik. Tidak ada kelanjutan dari berbagai program yang pernah dilaksanakan", tutur anggota yang lain.

Dalam hal perkembangan usaha, sangat jelas bahwa ada perbedaan antara usaha yang dimiliki TKI perempuan dan laki-laki. Para perempuan yang mengikuti Paguyuban Perintis sebagian besar memiliki usaha kecil yang mereka jalankan sendiri. Ada yang memiliki toko kelontong, warung makan, menjual bensin, menjahit, dan memiliki industri rumahan makanan ringan. Meskipun para TKI purna perempuan yang ikut dalam paguyuban ini telah memiliki usaha masingmasing, skala usaha yang dijalankan berbeda dengan para anggota paguyuban yang lakilaki. Beberapa anggota Paguyuban Perintis laki-laki sudah ada yang memiliki usaha pembuatan rempeyek dan mini-garmen yang mempekerjakan banyak orang, sementara kebanyakan usaha yang dijalankan para anggota paguyuban perempuan masih dikerjakan dan dikelola sendiri.

Perbedaan skala usaha yang dikembangkan antara anggota laki-laki dan anggota perempuan merupakan salah satu contoh bagaimana para TKI purna perempuan, dengan segala potensinya, belum sepenuhnya tersentuh oleh programprogram pemberdayaan TKI purna yang diberikan oleh pemerintah. Namun hal ini bukan berarti bahwa program-program pemberdayaan yang berikan oleh pemerintah memiliki kecenderungan untuk lebih menguntungkan laki-laki. Ada beberapa faktor yang mempengaruhi sukses atau tidaknya para TKI purna perempuan mengelola dan mengembangkan usahanya, yaitu pemahaman mengenai peran perempuan dalam keluarga, disparitas penghasilan antara TKI perempuan dan TKI laki-laki dan pengelolaan remiten. Temuan ini sejalan dengan penelitian (Imawan, 2016) dimana beban keluarga menjadi penghambat kegiatan di paguyuban, sebagaimana ditunjukkan dari hasil wawancara terhadap Rubiya sebagai berikut.

"Tergantung anak mas, kalau anak tidak sakit maka saya bisa ikut ke paguyuban. Kalau anak saya sakit, saya tidak bisa datang juga mas. Ya itu tadi mas, kalau ibu rumah tangga itu kurang ya (bukan domainnya). Itu bukan urusan perempuan, baiknya (bapak-bapak) yang muda-muda dan pengalaman saja mas." (Imawan, 2016: 79)

Hambatan mengikuti paguyuban juga merupakan salah satu hal penting untuk diperhatikan:

Khairun: "Iya mas, saya jarang karena repot sama anak. Karena kegiatan paguyuban itu biasanya malam mas. Makanya saya jarang ikut juga. Paling saya ikut paguyuban ibu-ibu satu $R T$, karena kalau paguyuban satu RT itu acaranya malam minggu. Berbeda kalau paguyuban satu kampung itu biasnaya malam minggu. Jadi saya repot." (Imawan, 2016: 83)

Informan lain, Mugiyah, menyatakan bahwa sebagai TKI purna, ia juga mendapatkan pelatihan-pelatihan dari pemerintah yang berkaitan dengan kewirausahaan namun bagi dia, "pelatihan ini sangat beragam dan tidak fokus. la mengatakan jika pelatihanpelatihan yang diterima bentuknya sangat beragam, mulai dari pelatihan membuat kue, menjahit, pembukuan, pemasaran dan lain sebagainya". Menurut Mugiyem, pelatihan yang menurutnya sangat berguna adalah pelatihan pembukuan dan pemasaran, 
sementara pelatihan-pelatihan seperti memasak dan menjahit, dirasa tidak terlalu bermanfaat karena kurangnya tindak lanjut dari pemerintah atau pemberi proyek. Mugiyah juga pernah mengikuti perkumpulan atau paguyuban di desa dan dusunnya, namun menurutnya sekarang perkumpulannya sedang tidak berjalan. "Pelatihan yang ada kurang memiliki manfaat karena tidak sesuai dengan kebutuhan saya. Sepertinya semua disesuaikan dengan kepentingan proyek. Perkumpulan juga tidak berjalan dengan baik."

Selain itu, Sudaryatmi pernah mengikuti perkumpulan TKI purna yang ada di dusunnya, namun ia sudah keluar. Perkumpulan TKI purna yang masih aktif, menurut Sudaryatmi, berada di dusun Sabrangan dan dusun Trukan. Ketika masih ada perkumpulan di dusun lain, ia mengatakan bahwa para TKI purna juga mendapatkan bantuan dan pelatihan. Sudaryatmi mendapatkan mesin jahit dengan mengikuti perkumpulan tersebut. la menambahkan bahwabantuan yang diberikan oleh pemerintah itu bermacam-macam. Tidak hanya mesin jahit, pemerintah juga bantuan berupa etalase barang dagangan bagi siapa pun yang ingin membuka usaha toko kelontong. Meski sudah diberi mesin jahit, Sudaryati mengaku kesulitan untuk membuka usaha karena yang ia hanya menerima pelatihan selama beberapa minggu di Jogja. Sudaryatmi mengaku sudah lama keluar dari paguyuban tersebut. Paguyuban TKI purna yang ada di Sungapan, sepengetahuan Sudaryatmi, bernama "Purna Maju" atau "Purna Jaya". Alasan keluar dari paguyuban tersebut adalah karena di salah satu acara atau agenda yang ada di paguyuban, koperasi simpan pinjam mewajibkan anggotanya untuk menabung atau membayar iuran setiap bulan. "Bagi saya, iuran dalam paguyuban merupakan beban, beban bagi saya dan keluarga karena tidak lagi bekerja. Dengan kondisi ini, lebih baik saya keluar dari grup". luran tersebut kemudian bisa diakses oleh anggota perkumpulan dengan proses simpan pinjam. Sudarmi mengatakan bagaimana dia bisa menjadi bagian dari kelompok Tani.

“... Iya Kelompok Wanita Tani. Walau saya tidak menggarap ladang, tapi itu perkumpulan ibu-ibu yang punya usaha. Fokusnya ya dengan orang yang mempunyai usaha tani. Tapi saya bisa gabung. Saya senang saja bisa bergabung, karena bisa dapat ilmunya seperti menanam cabe, terong, dan lain lain..... Di KWT itu kita saling berdiskusi mas. Terutama mengenai permasalahan usaha seperti kacang mete atau keripik pare. Paguyuban ini cukup membantu karena aktif saling memberikan masukan supaya usaha bisa lebih maju..... Ya tadi, yang tadinya tidak bisa menjadi bisa (dapat skill baru). Misalnya mengolah pisang, makanan kecil menjadi usaha makanan. Kalau bagi saya, keuntungannya ya, ibu-ibu jadi memesan kaos ke saya, itu untungnya buat saya karena saya berdagang kaos. Bisa menambah jaringan untuk usaha mas. (Imawan, 2016: 73-75)

Keberadaan paguyuban tidak selalu sejalan dengan kebutuhan para migran. Nia, seorang migran purna dari Korea mengungkapkan pengalaman selama mengikuti puguyuban sebagai berikut.

"Ada mas, tetapi karena acara paguyubannya hari minggu. Saya tidak bisa ikut, karena pabrik saya hari minggu tetap masuk kerja. Jadi selama di korea saya hanya pulang-kerja saja mas. Jarang 
ikut acara paguyuban. (setelah pulang), hanya urusan anak saja yang menghalangi. Kalau bisajalan (anak sudah bisa berjalan), kan bisa ditinggal (untuk bergabung ke paguyuban)"(Imawan, 2016: 161, 172)

\section{Supini:}

Hal yang jelas, masyarakat itu seperti itu. Ngemingke (meremehkan). Masyarakat itu kalau sudah ada hasilnya, baru tertarik untuk melakukan. Saya itu mau membuat desa wisata untuk TKI Purna saja susah sekali. Karena mentalitas mereka itu masih nge-drop, padahal kalau sudah ada desa wisata, itu artinya TKI-nya sudah tertata. Dan hal itu tidak bisa dikembangkan oleh satu orang. Kita nanti sebelum menjadi desa wisata, kita harus mempelajari sumber daya alam, sumber daya manusia, dan sumber daya wisata. Hal tersebut harus dipelajari secara benar (Imawan, 2016:142)

2. Peran dalam Keluarga sebagai Kendala Aktif di Paguyuban

Tugas sebagai istri dan ibu bagi anak menjadi kendala bagi TKI purna penempatan untuk aktif di paguyuban. Di sisi ini, tampak bahwa perempuan migran belum sepenuhnya mampu memiliki otonomi dalam mengambil keputusan. Kondisi ini menegaskan bahwa konsep perempuan sebagai pengurus rumah tangga ternyata mempunyai pengaruh yang cukup besar bagi perempuan untuk memutuskan terlibat dalam kegiatan paguyuban. Ketika para perempuan telah menikah keluarga dan/atau memiliki anak, mereka lebih memilih tinggal di rumah untuk mengurus anak dan memutuskan untuk mengurangi atau bahkan tidak terlibat dalam paguyuban, bahkan memutuskan untuk tidak bekerja kembali. Yati (40) memilih untuk tidak bekerja di luar negeri lagi setelah menikah karena ia merasa sebaiknya ia berada di Indonesia dan mengurus rumah tangga. la mengatakan bahwa sudah semestinya perempuan berada di rumah ketika sudah menikah, seperti mengurus rumah, memasak, mencuci, dan mengurus anak. la sebenarnya sudah beberapa kali ditawari untuk kembali bekerja ke Malaysia oleh majikannya, namun tawaran tersebut ia tolak karena Yati sudah memiliki satu anak saat tawaran tersebut diberikan.

Kendala lain adalah akumulasi modal yang berbeda antara TKI purna penempatan perempuan dan laki-laki. Adanya modal atau jumlah remitan yang berbeda menjadi sebab perbedaan kemampuan berkembangnya kegiatan ekonomi produktif. Cerita mengenai disparitas penghasilan antara TKI laki-laki dan TKI Perempuan diungkapkan oleh Ami (39), salah satu TKI perempuan asal Imogiri yang bekerja di PJTKI di Yogyakarta setelah pulang dari Malaysia dan Taiwan. Negaranegara yang menjadi tujuan populer bagi para TKI dari Yogyakarta, menurut Ami adalah Malaysia, Taiwan, dan Korea Selatan. la menambahkan bahwa ketiga negara tujuan tersebut juga mempunyai standar upah yang berbeda-beda. Jika diurutkan mulai dari yang tertinggi sampai yang terendah, Korea Selatan berada di posisi teratas dengan upah paling tinggi, sedangkan Taiwan berada di posisi kedua dan Malaysia berada di posisi terakhir sebagai negara dengan upah tenaga kerja yang paling rendah. Ami mengatakan jika penghasilan tertinggi yang bisa didapatkan TKI yang bekerja di Korea Selatan (pekerja pabrik) bisa mencapai 25 - 45 juta rupiah ditambah lembur, sedangkan mereka yang bekerja di Taiwan dan Malaysia (sama-sama 
pekerja pabrik) mendapatkan upah antara 5 sampai 20 juta rupiah dan sudah termasuk upah lembur.

Disparitas upah ini terjadi karena, menurut Emi, sebagian besar lowongan pekerjaan untuk perempuan datang dari Malaysia dan Taiwan, sedangkan lowongan pekerjaan yang berasal dari Korea Selatan, yang memiliki gaji yang besar, sebagian besar untuk lakilaki. Hal ini menunjukkan bahwa akses pekerjaan dengan penghasilan yang besar masih didominasi oleh laki-laki. Menurut Ami, alasan sebagian besar lowongan pekerjaan dari Korea Selatan untuk laki-laki adalah karena pekerjaan-pekerjaan yang tersedia menurutnya "Tidak cocok untuk perempuan". la menambahkan, "Ya misalnya mas, kalau disana satu gulungan benang itu beratnya lima kilogram, kalau harus membawa beberapa gulungan kan berat, jadi ya laki-laki cocoknya mas" kata Ami.

Ami telah keluar dari pekerjaannya di PJKTI karena ia tidak ingin meninggalkan anaknya yang masih kecil, menilai dirinya sendiri sebagai TKI purna yang "tidak berhasil". Menurutnya, TKI purna yang berhasil itu adalah mereka yang mampu memiliki usaha sendiri dan sudah mampu mempekerjakan karyawan. la memberikan contoh TKI purna dari Korea Selatan yang mendirikan restoran yang mampu menerima pesanan dengan partai besar, misalnya TKI purna yang sudah "sukses".

Ami menyimpulkan bahwa penyebab "Ketidakberhasilan" Ami sebagai TKI purna adalah pengelolaan gaji yang diterima saat bekerja di luar negeri. Meskipun Emi mengatakan bahwa gaji yang ia terima itu lebih besar jika bekerja di Indonesia, jika tidak ada "orang di rumah" yang mengelola uang tersebut menjadi usaha, maka akan sama saja. Saat masih bekerja di Malaysia dan
Taiwan, Ami belum menikah dan mengirimkan uang ke rumah saat orang tua meminta uang. Jika tidak ada permintaan, maka gaji yang ia dapatkan ia simpan sendiri di akun miliknya sendiri dan ia gunakan sesuai dengan keinginannya. la mengaku jika dirinya dulu "masih suka jalan-jalan" dan pulang dari Malaysia "tanpa membawa apa-apa". Sisa uang dari bekerja di Malaysia kemudian ia gunakan sebagai modal untuk berangkat ke Taiwan ketika ia merasa pekerjaan yang ada di Indonesia gajinya tidak sesuai. Berbeda dengan bekerja di Malaysia, Ami mengatakan bahwa ia mencoba untuk "hidup prihatin" di Taiwan dan menyisihkan uangnya untuk membangun rumah.

Hal ini berbeda dengan TKI purna penempatan laki-laki. Usaha rempeyek yang didirikan oleh Jumiran bersama dengan istrinya membawanya hingga ke seluruh Indonesia karena dinilai oleh pemerintah sebagai salah satu TKI purna yang "berhasil”. Usaha rempeyek itu berdiri sejak 2004, bahkan menurut Jumiran, usahanya mulai berdiri sebelum ia pulang ke Indonesia. Informan ini mengungkapkan kisah singkatnya sebagai berikut.

"Nah, kemungkinan juga dulu waktu itu minta uang dua juta setengah itu untuk produksi peyek. Saya itu dulu mikir, dua juta setengah untuk produksi peyek itu operasionalnya apa saja kan seperti itu... dulu yang merintis istri.. jadi istri saya kan dulu kerja di perpeyekan kemudian kalau untuk bekerja terus hasilnya seperti ini, bisakah untuk menghidupi keluarga, seperti itu, akhirnya berhenti... belajar sendiri... akhirnya ya ngebel saya ke Malaysia minta modal minta uang sejumlah itu tadi... itu pun saya baru dua bulan atau tiga bulan baru bisa mengembalikan hutang itu... hutang dulu saya waktu itu." 
Keluarga ini kembali melakukan usaha baru denganmembuka usaha tekstil. Hingga sekarang, usaha yang ia kembangkan sudah berjalan selama lima tahun. Sebagian besar modal yang ia gunakan untuk usaha tersebut ia dapatkan dari bank. Jumiran mengatakan bahwa ia lebih memilih untuk menggunakan uang, entah hasilnya dari mana, untuk membuka usaha daripada membuat rumah. "Rumah kan barang mati mas, nggak bisa diputar... kalau begini (menunjuk ke tempat produksi kaosnya) kan hidup uangnya, jadi bisa diputar".

Informan lain, Sukemi (perempuan), menjelaskan bahwa setelah dua tahun masa kontrak kerjanya habis di Malaysia, ia kembali ke Indonesia dan menikah. Tabungan selama dua tahun bekerja ia gunakan untuk membeli sapi, memperbaiki rumah dan membuka usaha kecil-kecilan berupa warung. Setelah enam bulan berada di rumah dan tidak ada pekerjaan, ia memutuskan untuk kembali lagi bekerja ke Malaysia dengan alasan untuk menambah modal usaha untuk warung yang baru ia buka tersebut. Setelah mendapatkan izin dari suaminya, Sukemi berangkat kembali ke Malaysia dan bekerja di pabrik yang sama, namun hanya bertahan selama satu tahun. Setelah bekerja untuk kedua kalinya, ia sudah tidak bekerja di luar negeri karena memiliki anak. la mengatakan bahwa sebenarnya ia bersedia dan suka bekerja di luar negeri. Namun ia lebih memilih untuk mengurus anak di rumah meskipun sudah beberapa kali diberikan tawaran untuk kembali bekerja ke luar negeri.

Warung tersebut ia dirikan setelah pertama kali kembali dari Malaysia. la mengembangkan usahanya tersebut dengan uang hasil bekerja dari keberangkatannya yang kedua. Kemudian ia memindahkan warung yang ia buat dari bambu dan kayu yang awalnya berada di dekat rumahnya ke pinggir jalan raya yang lebih ramai dan lebih dekat dengan pasar. la mengatakan bahwa dengan uang hasil kerjanya di Malaysia, ia mampu membuka warung, namun Sukemi tidak bisa hanya mengandalkan uang tersebut. Dengan demikian, ia juga membutuhkan uang dari sumber-sumber lain, misalnya dari keuntungan yang ia dapatkan dan pinjaman dari bank.

Data ini menjelaskan bagaimana sebagai seorang TKI purna, dengan penghasilan yang ia miliki dan seorang migran perempuan, masih sangat bergantung pada otoritas suami dalam menentukan jenis usaha dan keterlibatan dalam kegiatan di paguyuban. Pada akhirnya, kemungkinan kewirausahaan perempuan dapat berkembang sangat bergantung pada relasi-relasi internalkeluarga, pilihan-pilihan usaha, dan kemungkinan mereka dapat terintegrasi dengan kegiatankegiatan kelembagaan yang memungkinkan perempuan bisa lebih berkembang. Dalam kehidupan seorang migran dan komunitas, dampak sosial dari aktivitas migrasi tercermin dari dua hal, pertama, adanya wadah atau perkumpulan warga migran dan kedua, pola kewirausahaan yang dipilih dan berbagai jenis usaha yang ditekuni serta bagaimana pelibatan anggota keluarga lain dilakukan.

\section{Kesimpulan}

Proses feminisasi TKI merupakan fenomena penting dalam beberapa dasawarsa terakhir dan telah mampu mempengaruhi wajah dinamika sosial dan ekonomi perdesaan Jawa. Perubahan-perubahan relasi gender terjadi seiring meningkatnya peran ekonomi perempuan. Dalam kasus migrasi tenaga kerja, peran tinggi perempuan berarti bahwa terdapat peran ekonomi besar berupa remitan 
yang berasal dari TKI perempuan. Jumlah remitan yang besar mengharuskan adanya optimalisasi pemanfaatan remitan melalui kewirausahaan ekonomi dan sosial TKI purna. Keberhasilan penguatan TKI perempuan purna penempatan ini merupakan hal yang strategis. Dalam jangka panjang, peningkatan kualitas kehidupan rumah tangga TKI akan terjadi. Namun studi ini membuktikan bahwa remitan fisik (uang) maupun sosial (jaringan) perempuan purna penempatan ternyata tidak meningkatkan atau menguatkan peran ekonominya. Artikulasi peran dan posisi TKI purna perempuan dalam keluarga dan masyarakat dalam mengembangkan usaha (kewirausahaan sosial dan ekonomi) memiliki pengaruh signifikan dalam keberhasilan pengelolaan remitan. Mengapa kewirausahaan tenaga kerja perempuan purna penempatan gagal tercapai? Penelitian terhadap sejumlah TKI perempuan purna penempatan di Daerah Istimewa Yogyakarta menunjukkan, ada tiga hal penting yang mempengaruhi hal tersebut, yaitu rendahnya akumulasi pendapatan selama bekerja di luar negeri. Pertama, rendahnya akumulasi modal ini menjadi penyebab perempuan tidak bisa secara berkelanjutan tidak hanya menjalankan kegiatan ekonomi, tetapi juga terlibat dalam kegiatan paguyuban. Sementara itu, paguyuban sebenarnya memiliki posisi strategis karena merupakan salah suatu wadah yang tepat bagi berkumpulnya sesama PKI purna. Kedua, kondisi relasi gender internal keluarga. Banyak perempuan TKI purna penempatan yang masih terbebani peran-peran domestik dan memilih untuk tetap menjalankan peran domestik dengan mengalahkan peluang untuk maju ketika mereka bergerak aktif dalam kegiatan publik (paguyuban). Ketiga, rendahnya kapasitas fasilitas dari institusi perubahan sosial terhadap keluarga-keluarga migran yang ditandai dengan tidak adanya program yang berkelanjutan

\section{Daftar Pustaka}

Abas, S., \& Purnomo, R. A. (2017). Peran Mentor Bisnis Bagi Tki Pasca Migrasi Untuk Berwirausaha. Optimal: Jurnal Ekonomi Dan Kewirausahaan, 11(2), 120-137. https://doi.org/10.33558/optimal.v11i2.748.

Anwar, R. P. (2015). Return Migration and Local Development in Indonesia. 현대사회와 다문화 (Modern Society and Multiculturalism), 5(2), 224-257.

Ariefianto, L., \& Ulum, M. B. (2019). Pelatihan Inovasi Pepaya bagi Perempuan Purna Buruh Migran di Desa Sabrang Kecamatan Ambulu Kabupaten Jember. Warta Pengabdian, 13(4), 136. https://doi. org/10.19184/wrtp.v13i4.10777.

Arifiartiningsih. (2016). Pemberdayaan Mantan Buruh Migran. Sosiologi Reflektif, 11(1), 109-138.

Asriani, D. D., \& Amalia, E. (2014). Jejak Perempuan Buruh Migran dalam Masyarakat ASEAN 2015. Jurnal IImu Sosial Dan IImu Politik, 18(2), 147-159. https://doi.org/10.22146/jsp.13129.

Basrowi, B. (2019). Dampak Pekerja Migran Perempuan Terhadap Status Sosial Ekonomi Keluarga, Tingkat Pendidikan, dan Kesehatan Anak. Kafa 'ah: Journal of Gender Studies, 9(1), 63. https://doi. org/10.15548/jk.v9i1.232.

BP2MI. (2020). Data Penempatan dan Perlindungan PMI Periode februari 2020. In Pusat Data dan Informasi BP2MI. https://doi.org/10.1017/CBO9781107415 324.004.

BP3TKI. (2015). Jumiran TKI Purna Sukses

Asal Bantul Yogyakarta. http://tkipurna. bp3tkiyogya.info/berita-jumiran-tki-purnasukses-asal-bantul-yogyakarta.html. 
Brettell, C. B. (2013). Anthropology of migration. The Encyclopedia of Global Human Migration, 1-5. https://doi. org/10.1002/9781444351071. wbeghm031. Chan, C. (2014). Gendered morality and development narratives: The case of female labor migration from Indonesia. Sustainability (Switzerland), 6(10), 69496972. https://doi.org/10.3390/su6106949.

De Jong, G. F. (2000). Expectations, gender, and norms in migration decisionmaking. Population Studies: A Journala of Demography, 54(3), 307-319. https://doi. org/10.1080/713779089.

Dewi, M. K., Zulaikha, S., Puspasari, N., Luhita, T. Dela, \& Banyumas, K. (2018). PROGRAM KEWIRAUSAHAAN PEKERJA MIGRAN DALAM. Pengembangan Sumber Daya Perdesaan Dan Kearifan Lokal Berkelanjutan VIII 14-15 November, 204-210. Purwokerto.

Hage, G. (2005). A not so multi-sited ethnographyofanotsoimaginedcommunity. Anthropological Theory, 5 (4), 463-475. https://doi.org/10.1177/1463499605059 232.

Hugo, G. (2002). Effects of international migration on the family of Indonesia. Asian and Pacific Migration Journal, 11(1), 13-46. https://doi.org/10.1177/01171968 0201100102.

Imawan, R. P. (2016). Is the International migration fostering social capital? A field study on the effects of international migration experience on social capital in Javanese society in Bantul, Indonesia. Thesis. Departement of Government UPPSALA UNIVERSITY.

Jaya, N. N., \& Subrata, I. G. M. (2014). Model kewirausahaan pada pemberdayaan buruh. GaneÇ Swara, 8(2), 65-69. Retrieved from unmasmataram.ac.id/wp/wp-content/ uploads/10.-Nata-dan-Berata.pdf.
Katherine Gibson, L. L. \& D. M. (2001). Beyond Heroes and Victims. International Feminist Journal of Politics ISSN:, 3(3), 365-386. https://doi. org/10.1080/1461674011007818.

Kirana, K. C., Kusrini, K., \& Purwanto, M. I. (2017). Analisis Faktor Intensi Kewirausahaan Tenaga Kerja Wanita Purna Gunung Kidul Untuk Kemandirian. EKUITAS (Jurnal Ekonomi Dan Keuangan), 1(3), 303-324. https://doi.org/10.24034/ j25485024.y2017.v1.i3.2404.

Komariah, Kokom, S. dan M. (2019). Pengembangan Kapasitas Buruh Migran Melalui Pelatihan Pembuatan Produk Kreatif Kewirausahaan. Jurnal Pengabdian Dan Pengembangan Masyarakat, II(1), 157-166.

Lem, W. (2007). William roseberry, class and inequality in the anthropology of migration. Critique of Anthropology, 27(4), 377-394. https://doi. org/10.1177/0308275X07084231.

Listyani, R. H., \& Kharisma, I. (2006). Umkm: wujud kemandirian ekonomi perempuan menuju perekonomian global. Al-'Adalah, 19(1), 107-126.

Mahler, S. J., \& Pessar, P. R. (2006). Gender matters: Ethnographers bring gender from the periphery toward the core of migration studies. International Migration Review, 40(1), 27-63. https://doi.org/10.1111/ j.1747-7379.2006.00002.x.

Meiliyana, M. (2019). Organizing Return Migrant Workers From Indonesia for Sustainable Governance. Wacana Publik, 13(01), 33-44. https://doi.org/10.37295/ wp.v13i01.26.

Mihradi, R. M., \& Siregar, F. M. (2018). Dinamika Problematika Sosial Perlindungan Buruh Migran Indonesia Pasca Reformasi Dan Relevansinya Dengan Tantangan Wirausaha Di Era 
Masyarakat Ekonomi Asean (Mea). Jurnal Kawistara, 7(2), 115-206. https://doi. org/10.22146/kawistara.23657.

Muntamah,A. L., Latifiani, D., \&Arifin, R. (2016). PERNIKAHAN DINI DI INDONESIA: FAKTOR DAN PERAN PEMERINTAH (PERSPEKTIF PENEGAKAN DAN PERLINDUNGAN HUKUM BAGI ANAK). Widya Yuridika Jurnal Hukum, 21(1), 1-12. Nana, \& Oishi. (2002). Gender and Migration: An Integrative Approach Gender and Migration: An Integrative Approach. CCIS CCIS THE CENTER FOR COMPARATIVE IMMIGRATION STUDIES.

Pitoyo, A. J. (2006). Pemagangan Luar Negeri tenaga Kerja: Proses, Pendapatan, dan Alih Teknologi. Populasi, 17(1), 41-.

Prihanto, P. H. (2014). PENGARUH STATUS PEKERJAAN DAN NEGARA PENEMPATAN TERHADAP REMITANSI PEKERJA MIGRAN INDONESIA. Jurnal Paradigma Ekonomica, 9(2), 33-41.

Primawati, A. (2011). Dampak Migrasi Pekerja ke Malaysia Terhadap Perubahan dan Modernisasi Daerah Asal. Sosiologi Andalas, 11, 195-216.

Purnomo, et.al. (2009). STUDI TENTANG MIGRASI TENAGA KERJA DAN PERANNYA BAGI PEMBANGUNAN DAERAHASAL(StudiEmpiris di Kabupaten Wonogiri. LAPORAN AKHIR (TAHUN II) HIBAH PENELITIAN KERJASAMA ANTAR PERGURUAN TINGGI (HBAH PEKERTI) TAHUN ANGGARAN 2009.LEMBAGA PENELITIAN DAN PENGABD.

Putri, O. N., \& Darwis, R. S. (2015). Pemberdayaan Perempuan Kepala Keluarga. Prosiding Penelitian Dan Pengabdian Kepada Masyarakat, 2(2), 279-283. https://doi.org/10.24198/jppm. v2i2.13538.

Rahayu, Devi dan Munir, M. (2012). Alternatif Kebijakan Peraturan Daerah Perspektif
Gender Bagi Buruh Migran Perempuan Di Madura. Mimbar Hukum, 24(3), 554-569. https://doi.org/10.22146/jmh.16125.

Rahmawati, R., Demartoto, A., \& Soemanto, R. B. (2017). Analisis Perspektif Gender dalam Pola Perilaku Purna Migran Perempuan di Sragen. Jurnal Analisa Sosiologi, 6(2), 64-75.

Romdiati, H. (2012). Migrasi Tenaga Kerja Indonesia Dari Kabupaten Tulungagung: Kecenderungan dan Arah Migrasi, serta Remitansi. Jurnal Kependudukan Indonesia, VII(2), 27-53.

Sagala, S., Pratama, A. A., \& Argo, T. A. (2016).

Peran Remitan Tenaga Kerja Indonesia Terhadap Potensi Pengurangan Risiko Bencana Banjir Di Wilayah Perkotaan Indramayu. Tataloka, 14(1), 37-51. https:// doi.org/10.14710/tataloka.14.1.37-51.

Sudarsani, N. P., Sukarsa, I. M., \& Marhaeni, A. A. I. N. (2015). ANALISIS FAKTORFAKTOR YANG MEMPENGARUHI PENDAPATAN PEKERJA. E-Jurnal Ekonomi Dan Bisnis Universitas Udayana, 4(8), 522-536.

Sugito, T., Windiasih, R., \& Sulaiman, A. I. (2018). Aktualisasi Pembangunan Partisipatif Dalam Forum Komunikasi Pemberdayaan Perempuan Desa. Journal Acta Diurna, 14(1), 1-16. Retrieved from http://jos.unsoed.ac.id/index.php/acta_ diurna/article/view/1138.

Sulistyono, S. W. (2015). Peran Karakter SosialEkonomi Sebagai Pendorong Menjadi TKI (Studi Kasus di Kecamatan Selorejo Kabupaten Selorejo). Jurnal Ekoniomi \& Studi Pembangunan, 7(2), 51-60.

Susilo, S. (2018). Remittance Management in Realizing a Prosperous Houshold of Indonesian Migrant Workers (TKI) on Remoted Communities in Bawean Island Indonesia. The Social Sciences, 13(8), 1328-1332. 
Truong, T. D. (1996). Gender, international migration and social reproduction: Implications for theory, policy, research and networking. Asian and Pacific Migration Journal, 5(1), 27-52. https://doi. org/10.1177/011719689600500103.

Utama Agung, Handayani, T. K. W. (2019). Model Pemberdayaan Perempuan Miskin Melalui Pelatihan Kewirausahaan Berbasis Potensi Lokal di Kecamatan Wedi Kabupaten Klaten. Jurnal Penelitian Humaniora, 19(2), 154-167. https://doi. org/10.1017/CBO9781107415324.004.

van Hear, N. (2010). Theories of migration and social change. Journal of Ethnic and Migration Studies, 36(10), 15311536. https://doi.org/10.1080/136918 3X.2010.489359.

Vertovec, S. (2007). Introduction: New directions in the anthropology of migration and multiculturalism. Ethnic and Racial Studies, 30(6), 961-978. https://doi. org/10.1080/01419870701599416.

Windiasih, O. R., \& Sugito, T. (2018). Pemberdayaan masyarakat buruh migran. Pengembangan Sumber Daya Perdesaan Dan Kearifan Lokal Berkelanjutan VIII, (November), 410-422.

Wulan, T.R, Shodiq, D., Wijayanti, S., Lestari, D. W. ., Hapsari, A. ., Wahyuningsih, E., \& Restuadhi, H. (2018). Ayah Tangguh, Keluarga Utuh: Pola Asuh Ayah pada Keluarga Buruh Migran Perempuan di Kabupaten Banyumas. Jurnal IImu
Keluarga Dan Konsumen, 11(2), 84-95. https://doi.org/10.24156/jikk.2018.11.2.84.

Wulan, Tyas Retno, et.al., (2009). Strategi Pemberdayaan Buruh Migran Perempuan Indonesia Di Hongkong. Jurnal AGRISEP, 8(2), 59-72. https://doi.org/10.31186/ jagrisep.8.2.59-72.

Yuniarto, P. R. (2012). Dari Pekerja ke Wirausaha: Migrasi Internasional, Dinamika Tenaga Kerja, dan Pembentukan Bisnis Migran Indonesia di Taiwan. Jurnal Kajian Wilayah, 3(1), 73-102. https://doi. org/10.14203/JKW.V3I1.312.

Yuniriyanti, Eny, Sudarwati, Ririn dan Nurdewanto, B. (2019). PEMBERDAYAAN PEREMPUAN DESA BERBASIS KEARIFAN LOKAL DALAM UPAYA PENCAPAIAN KETAHANAN PANGAN KELUARGA (Studi pada Purna Perempuan Pekerja Migran Indonesia-Desa DrujuKabupaten Malang). Seminar Nasional Sistem Informasi, (September), 17081719.

Yusa, M., Hadinegoro, A., \& Fatkhurohman, A. (2018). Prosiding IMPLEMENTASI teknologi tepat guna kepada masyarakat. Seminar Hasil Pengabdian Masyarakat, 1(1), 193-198. 